\title{
A Design of Quad-Band Hexagonal Antenna with Fractal Slots using Inset Feeding Technique
}

\author{
Jaspreet Singh \\ M.Tech Scholar \\ Electronics and Communication \\ Engineering Deptt. \\ Amritsar College of \\ Engineering and Technology, \\ Amritsar
}

\author{
Narinder Sharma \\ Associate Professor \\ Electronics and Communication \\ Engineering Deptt. \\ Amritsar College of \\ Engineering and Technology, \\ Amritsar
}

\begin{abstract}
In this paper, a hexagonal patch antenna is presented for wireless applications. Proposed antenna is designed on low cost FR4 glass epoxy substrate with relative permittivity of 4.4 and thickness $1.6 \mathrm{~mm}$. The quad band behavior is obtained by using inset feeding technique. The centre frequencies of the operating bands are $3.55 \mathrm{GHz}, 5.94 \mathrm{GHz}, 8.50 \mathrm{GHz}$ and $9.47 \mathrm{GHz}$. Values of return loss and VSWR are at the acceptable level for each frequency bands of operation. Antenna parameters like gain, bandwidth and radiation pattern are also observed and analyzed in this paper. HFSS V13 software is used to design and simulating the proposed antenna. The antenna can be used for different applications such as wireless point to point communication, WLAN and Xband.
\end{abstract}

\section{Keywords}

Hexagonal, VSWR, HFSS, gain, bandwidth.

\section{INTRODUCTION}

Different types of fractal structures had been developed by the researchers. B. Mandelbort was the first to describe the complex structure of fractal antenna in 1975 [1] [2]. In recent years the fractal antennas experienced a large growth in the field of wireless communication, due to its many advantages like multiband behavior, small size and fulfill the need of modern communication [3]. Fractal is a rough geometric structure and is divided into sub-parts, where each part is a reduced copy of the whole structure [4]. Two properties are used to design the geometries of fractal antennas, one is selfsimilarity and the other is space-filling [5] [6]. Self-similarity property of fractal is used to divide the parts of whole structure at different scales and space-filling is used to achieve the miniaturization of antenna [7]. The geometries of fractal antenna are designed to achieve the wideband and multiband characteristics which are the need of modern wireless communication systems [8]. There are many structure of antenna has been designed by the researchers such as Contors set, Koch curves, Sierpinski carpet, Sierpinski gasket, Meander, Minkowski etc [9].

In this paper a hexagonal antenna with fractal slots has been designed. The line feed and inset line feeding techniques are applied to analyze the behavior of designed antenna. Different parameters have been observed at different frequency bands of operation. The detailed design of antenna and all the simulated results of the proposed antenna are discussed in section 2 and 3 respectively.

\section{ANTENNA DESIGN}

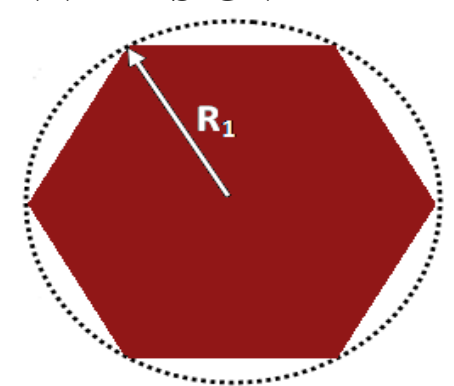

Figure 1: Proposed antenna initial geometry

Figure 1 shows the initial geometry of proposed antenna. The radius of hexagonal shaped patch is calculated by using equations (1) to (3) as $R_{1}=12.6 \mathrm{~mm}$. To calculate the radius of circle different parameters has been taken into consideration such as dielectric constant, height of substrate and resonant frequency of antenna. In this design FR4 glass epoxy substrate with dielectric constant 4.4 , height of substrate $1.6 \mathrm{~mm}$ and resonant frequency of $3.2 \mathrm{GHz}$ is used.

$$
\begin{aligned}
& a=F\left\{1+\frac{2 h}{\pi F \varepsilon_{r}}\left[\ln \left(\frac{\pi F}{2 h}\right)+1.7726\right]\right\}^{-1 / 2} \\
& F=\frac{8.791 \times 10^{9}}{f_{r} \sqrt{\varepsilon_{r}}} \\
& a_{e}=a\left\{1+\frac{2 h}{\pi a \varepsilon_{r}}\left[\ln \left(\frac{\pi a}{2 h}\right)+1.7726\right]\right\}^{1 / 2}
\end{aligned}
$$

Where;

$$
\begin{aligned}
& a=\text { radius of circle } \\
& a_{e}=\text { effective radius of circle } \\
& c=\text { velocity of light in free space } \\
& f_{r}=\text { resonant frequency } \\
& h=\text { height of substrate } \\
& \varepsilon_{r}=\text { dielectric constant of substrate }
\end{aligned}
$$




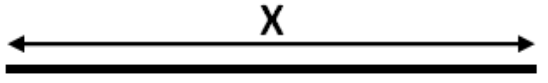

(a)

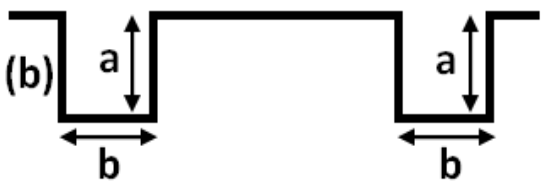

Figure 2: (a) Initiator and (b) procedure for designing fractal slots

The initiator as shown in Figure 2 (a) depict the one side of the hexagonal geometry of patch out of six sides and the length $\mathrm{X}=12.6 \mathrm{~mm}$. The fractal slots has been designed as shown in Figure 2 (b) with length $\mathrm{a}=1.4 \mathrm{~mm}$ and width $\mathrm{b}=1.4 \mathrm{~mm}$. Geometry with fractal slots is applied to all the six sides of the hexagonal geometry of patch to obtain the final geometry of the patch of proposed antenna. The line feeding technique is applied to provide the excitation to the proposed antenna as shown in Figure 3. To enhance the performance of designed antenna an inset cuts are applied to the feed line as shown in Figure 4. Parametric values of proposed antenna are shown in Table 1. The performance of antenna with and without inset feeding technique is discussed in section 3.

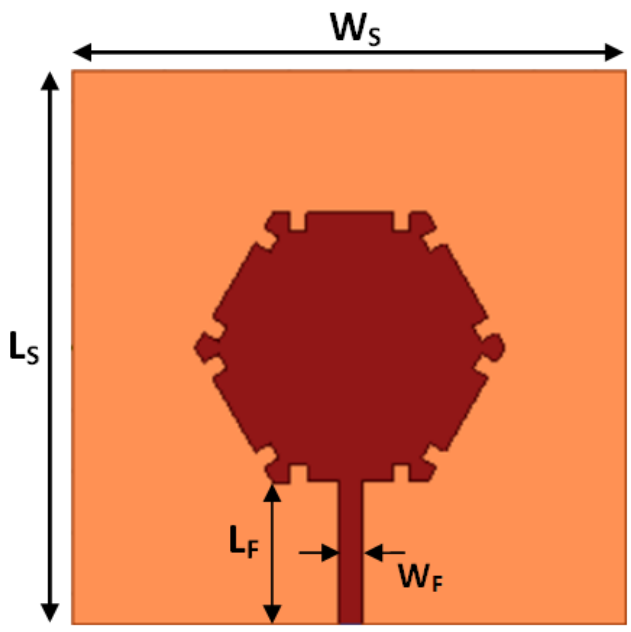

Figure 3: Proposed antenna without inset feed

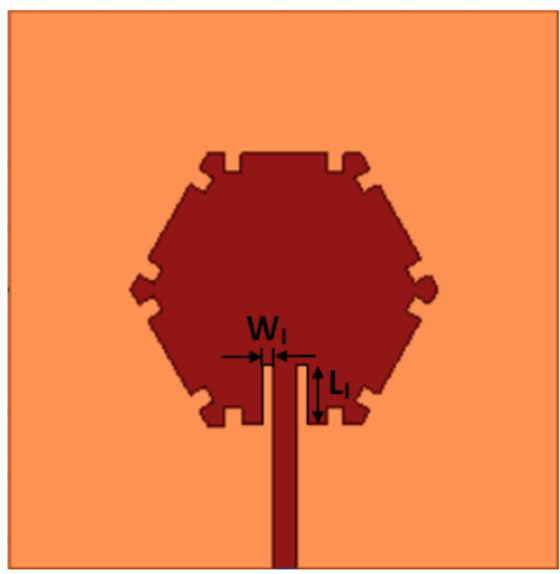

Figure 4: Proposed antenna with inset feed
Table 1: Proposed antenna parametric values

\begin{tabular}{|c|c|c|c|}
\hline S. No. & Parameters & Description & Values \\
\hline 1. & $\mathrm{~W}_{\mathrm{S}}$ & Width of Substrate & $45 \mathrm{~mm}$ \\
\hline 2. & $\mathrm{~L}_{\mathrm{S}}$ & Length of Substrate & $44.92 \mathrm{~mm}$ \\
\hline 3. & $\mathrm{~W}_{\mathrm{F}}$ & Width of Feed & $1.80 \mathrm{~mm}$ \\
\hline 4. & $\mathrm{~L}_{\mathrm{F}}$ & Length of Feed & $11.54 \mathrm{~mm}$ \\
\hline 5. & $\mathrm{~W}_{\mathrm{I}}$ & Width of inset cut & $1 \mathrm{~mm}$ \\
\hline 6. & $\mathrm{~L}_{\mathrm{I}}$ & Length of inset cut & $3.5 \mathrm{~mm}$ \\
\hline 7. & $\mathrm{X}$ & Length of initiator & $12.6 \mathrm{~mm}$ \\
\hline 8. & $\mathrm{a}$ & Length of fractal slot & $1.4 \mathrm{~mm}$ \\
\hline 9. & $\mathrm{~b}$ & Width of fractal slot & $1.4 \mathrm{~mm}$ \\
\hline
\end{tabular}

\section{RESULT AND DISCUSSIONS}

\subsection{Return loss and VSWR}

Return loss versus of frequency plot of proposed antenna without inset feed and with inset feed is depicted in Figure 5 and Figure 6 respectively.

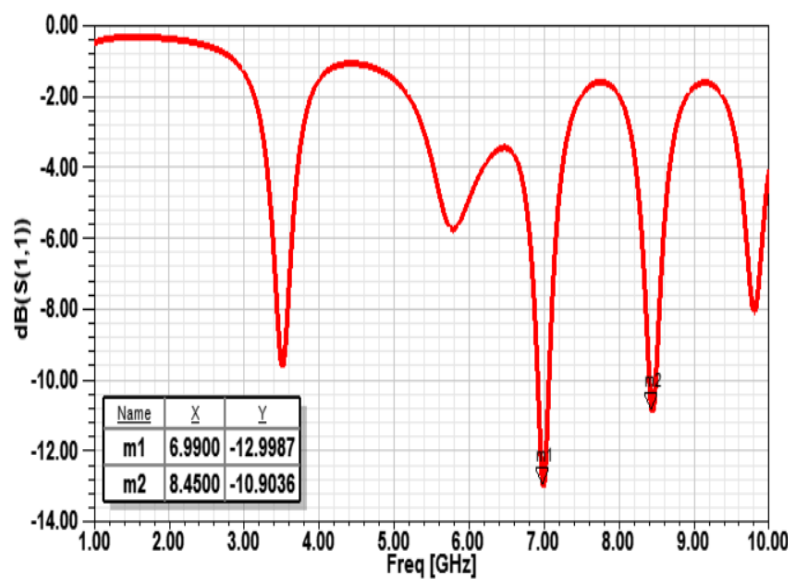

Figure 5: Return loss curve of antenna without inset cut

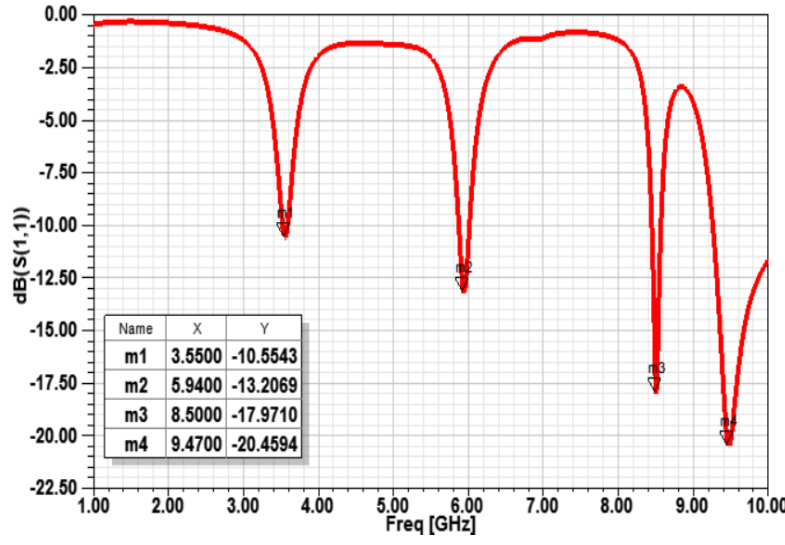

Figure 6: Return loss curve of antenna with inset cut

The antenna with inset feed works on two resonant frequency bands such as $6.99 \mathrm{GHz}$ and $8.45 \mathrm{GHz}$. Proposed antenna with inset feed works on four frequency bands of operation such as $3.55 \mathrm{GHz}, 5.94 \mathrm{GHz}, 8.50 \mathrm{GHz}$ and $9.47 \mathrm{GHz}$. By observing both the return loss curves of proposed antennas, it has been concluded that the frequency of antenna shifted toward lower side without affecting the dimensions of antenna. The shifting of frequency band is achieved by introducing the inset feeding technique in the proposed geometry of antenna. The values of return loss at all the frequency bands are at acceptable level (return loss less than -10dB). VSWR versus of frequency curves of proposed antenna for both the geometries are depicted in Figure 7 and Figure 8 respectively. Values of 
VSWR at all the frequency bands are also at acceptable level (VSWR less than 2). The values of return loss, VSWR and bandwidth at all the frequency bands for both the geometries of proposed antenna are shown in Table 2.

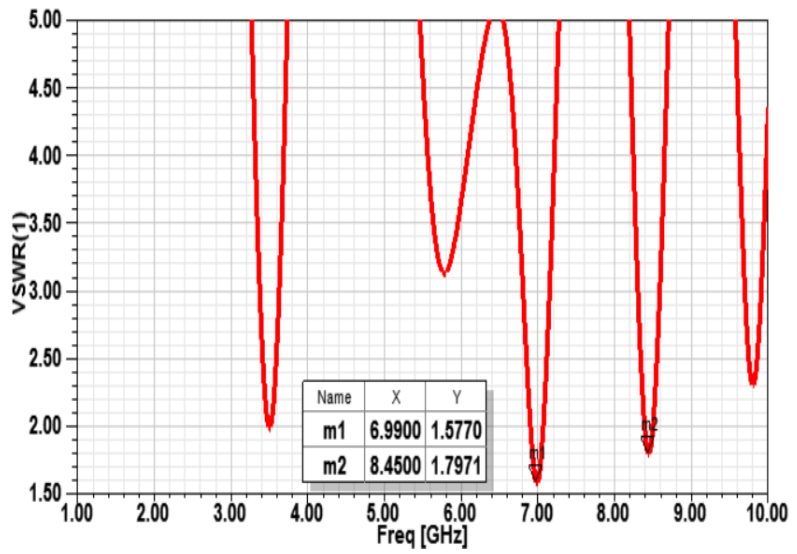

Figure 7: VSWR curve of antenna without inset cut

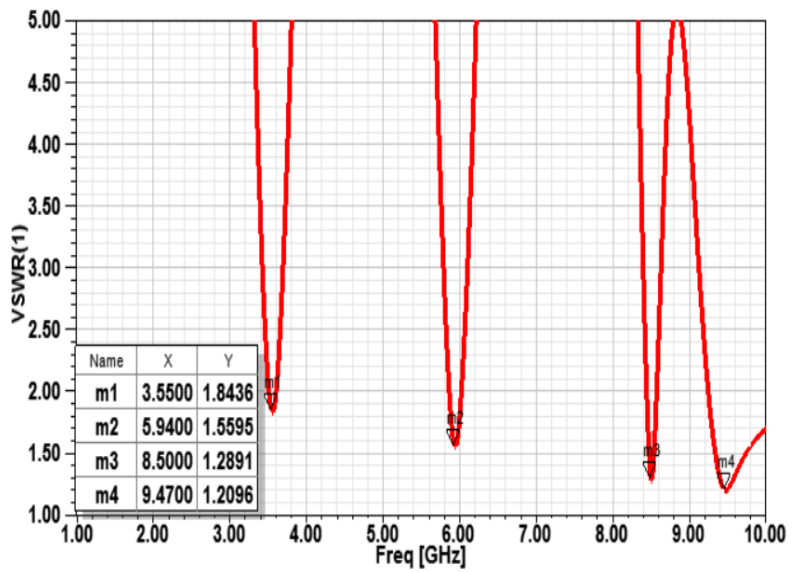

Figure 8: VSWR curve of antenna with inset cut

Table 2. Proposed antenna simulated results

\begin{tabular}{|c|c|c|c|c|}
\hline $\begin{array}{c}\text { Proposed } \\
\text { Antenna }\end{array}$ & $\begin{array}{c}\text { Frequency } \\
(\mathbf{G H z})\end{array}$ & $\begin{array}{c}\text { Return } \\
\text { Loss } \\
\text { (dB) }\end{array}$ & VSWR & $\begin{array}{c}\text { Band } \\
\text { width } \\
\text { (MHz) }\end{array}$ \\
\hline \multirow{2}{*}{$\begin{array}{c}\text { Without } \\
\text { inset feed }\end{array}$} & 6.99 & -12.99 & 1.57 & 150 \\
\cline { 2 - 5 } & 8.45 & -10.90 & 1.79 & 80 \\
\hline \multirow{3}{*}{$\begin{array}{c}\text { With inset } \\
\text { feed }\end{array}$} & 3.55 & -10.55 & 1.84 & 60 \\
\cline { 2 - 5 } & 5.94 & -13.20 & 1.55 & 130 \\
\cline { 2 - 5 } & 8.50 & -17.97 & 1.28 & 120 \\
\cline { 2 - 5 } & 9.47 & -20.45 & 1.20 & 750 \\
\hline
\end{tabular}

\subsection{Gain and Radiation pattern}

The gain of proposed antenna is simulated at all the resonant frequencies for both the geometries of proposed antenna. Value of gain is at the acceptable level as shown in Table 3. Radiation pattern is the graphical representation of relative field strength of antenna. The useful portion of radiation pattern is at phi $=0^{\circ}$ and $p h i=90^{\circ}$. The $2 \mathrm{D}$ radiation pattern and 3D gain plot of antenna for both the geometries at different frequency bands is shown in Figure 9 and Figure 10 respectively.

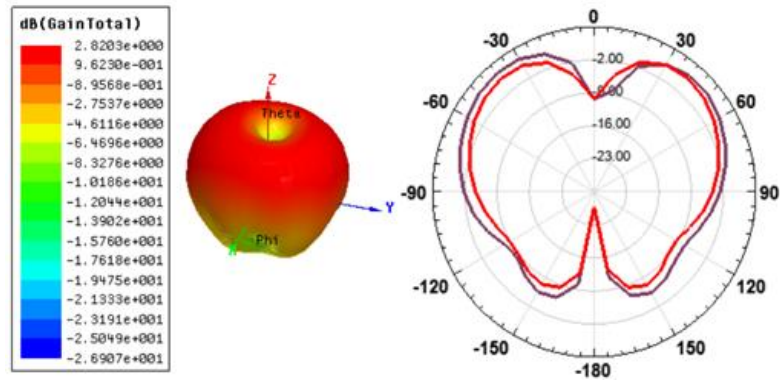

(a)

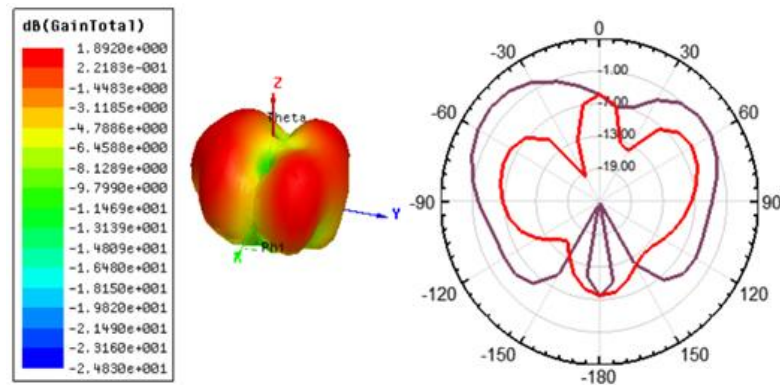

(b)

Figure 9: 2D radiation pattern and 3Dgain plot at (a) $6.99 \mathrm{GHz}$ and $(\mathrm{b}) 8.45 \mathrm{GHz}$ frequency band
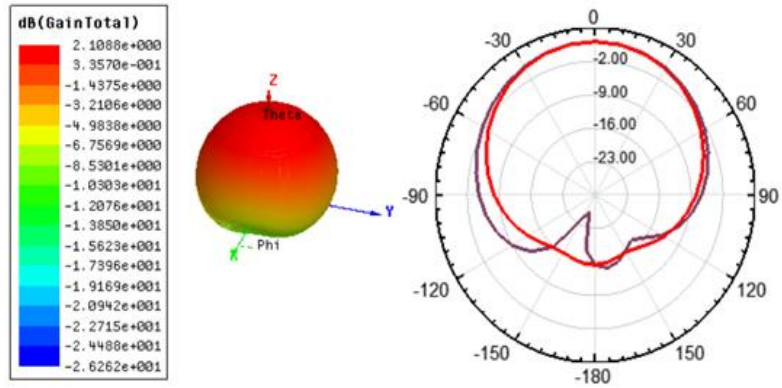

(a)
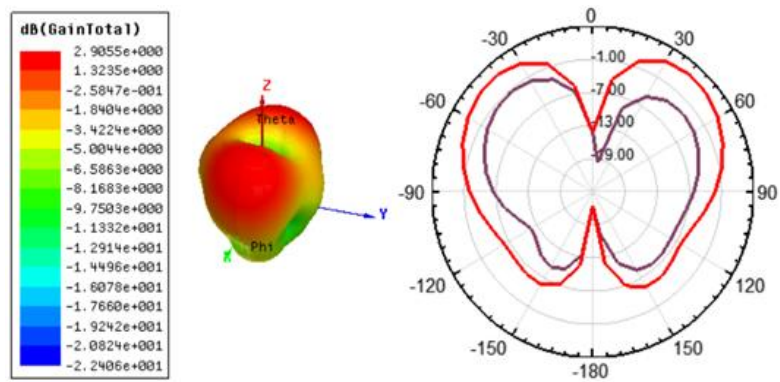

(b)
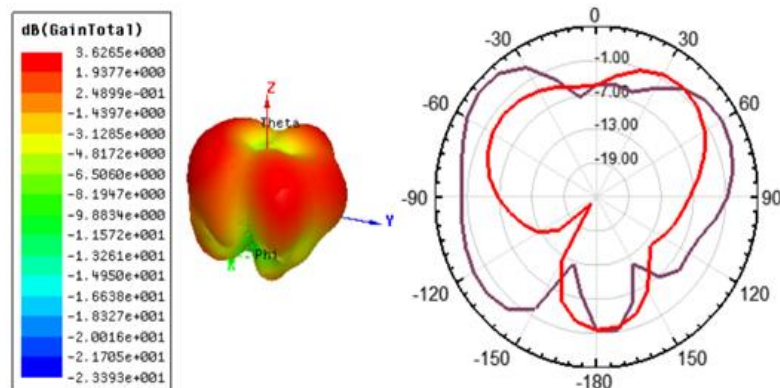

(c) 


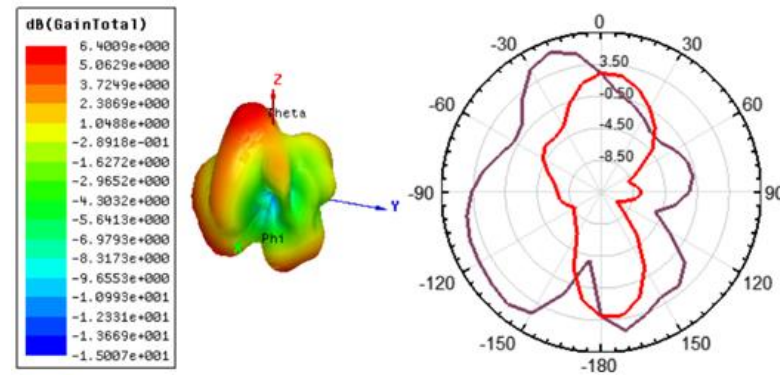

(d)

Figure 10: 2D radiation pattern and 3Dgain plot at (a) $3.55 \mathrm{GHz}$, (b) $5.94 \mathrm{GHz}$, (c) $8.50 \mathrm{GHz}$ and (d) $9.47 \mathrm{GHz}$ frequency band

Table 3. Simulated gain of proposed antenna

\begin{tabular}{|c|c|c|}
\hline $\begin{array}{c}\text { Proposed } \\
\text { Antenna }\end{array}$ & $\begin{array}{c}\text { Frequency } \\
(\mathbf{G H z})\end{array}$ & Gain(dB) \\
\hline \multirow{2}{*}{ Without inset feed } & 6.99 & 2.82 \\
\cline { 2 - 3 } & 8.45 & 1.89 \\
\hline \multirow{3}{*}{ With inset feed } & 3.55 & 2.10 \\
\cline { 2 - 3 } & 5.94 & 2.90 \\
\cline { 2 - 3 } & 8.50 & 3.62 \\
\cline { 2 - 3 } & 9.47 & 6.40 \\
\hline
\end{tabular}

\section{CONCLUSIONS}

This paper presents the design of hexagonal antenna with fractal slots for wireless applications such as WLAN, $\mathrm{x}$-band and wireless point to point communication. Inset feeding technique is applied to achieve the quad-band behavior of proposed antenna. The frequency is also shifted towards the lower side without affecting the antenna dimensions. Gain and bandwidth of proposed antenna is also calculated at each frequency band. Value of maximum gain and bandwidth is $6.40 \mathrm{~dB}$ and $750 \mathrm{MHz}$ respectively at $9.47 \mathrm{GHz}$ frequency band. The value of return loss and VSWR is also at acceptable level.

\section{REFERENCES}

[1] B. You, T. Xue, Y. Zhao, J. Zhou, T. Wang and J. Li, "A dual-band S-shaped fractal orthogonal dipole antenna for vehicular navigation system," IEEE, APEMC, pp. 158$161,2015$.

[2] A. Kaur and N. Sharma , "A quad band circular patch antenna with fractal elements for S-band and C-band applications," International Journal of Computer Applications, Vol. 144, No. 3, pp. 1-4, 2016.

[3] P. Z. Petkov, M. R. Kolev and B. G. Bonev, "Fractal Yagi Antenna," IEEE, International Conference on Microwave Techniques (COMITE), pp. 1-3, 2015

[4] K. Kharat, S. Dhoot and J. Vajpai, "Design of compact multiband fractal antenna for WLAN and WiMax applications," IEEE, International Conference on Pervasive Computing (ICPC), 205.

[5] A. E. Hamdouni, J. Zbitou, A. Tajmauati, L. E Abdellaoui, A. Errikik, A. Tribak and M. Latrach, "A novel design of a CPW-fed printed fractal antenna for UWB applications," IEEE, pp. 38-41, 2015.

[6] J. S. Sivia and S. S. Bhatia, "Design of fractal based microstrip rectangular patch antenna for multiband applications," IEEE International Advance Computing Conference (IACC), pp. 712-715, 2015.

[7] V. Dinesh and G. Karunakar, "Analysis of microstrip rectangular carpet shaped fractal antenna," IEEE, SPACES, pp. 531-535, 2015.

[8] R. Teotia and T. Shanmuganantham, "CPW- fed dodecagram fractal antenna with DGS for multiband applications," IEEE, International Conference on Signal Processing, Informatics, Communication and Energy Systems (SPICES), pp. 1-5, 2015.

[9] M. Benazir and P. Jothilakshmi, "Circular patch with star triangular fractal antenna for SWB applications," International Conference on Communication and Signal Processing," pp. 485-489, 2014 